\title{
12 INDIVIDUAL, ORGANIZATIONAL, AND SOCIETAL PERSPECTIVES ON INFORMATION DELIVERY SYSTEMS: BRIGHT AND DARK SIDES TO PUSH AND PULL TECHNOLOGIES
}

\author{
Julie E. Kendall \\ Rutgers University \\ U.S.A. \\ Kenneth E. Kendall \\ Rutgers University \\ U.S.A.
}

\begin{abstract}
Two competing visions of humans and whether they eschew or embrace the use of pull and push technologies can help us to envision the future. It is said that George Orwell feared that what we hate will ruin us. On the other hand, Aldous Huxley feared that what we love will ruin us (Postman 1985). Information delivery systems, also called pull and push technologies, are ways to obtain and deliver information to users. This article briefly reviews the types of pull and push technologies, then goes on to explore the major benefits of both pull and push. But as the benefits of information delivery systems are elaborated, the darker side of push and pull are also exposed. Some alarming possibilities for future use of these technologies are identified, but this article goes on to discover and create both
\end{abstract}


remedies and resolution mechanisms to counter the threats to individuals, organizations, and society. When remedies have no effect, the alternative may be unplugging.

\section{Introduction}

Information delivery systems (IDS) is used as a collective term to include both pull and push technologies for obtaining materials over the Internet (and its successors). In the first section of the paper, we explore the world of a person making use of pull technology, or seeking out information on the Web. The term pull technology can mean simply surfing the Net to allowing an ever changing, independent evolutionary agent explore the Web for you. The term push technology can be used to describe anything from broadcasting to selective content delivery with sophisticated evolutionary filtering using data mining techniques.

Decision makers need no longer surf the Net or use simple search engines with little precision or unsatisfactory recall. The advent of advanced push technologies means that content is delivered to users on a periodically scheduled basis, without the need for a user request (Richardson 1997). Push technology is an efficient way to feed content to millions of consumers simultaneously (if desired). However, push technology, which takes advantage of several new developments that enable Web-based material to be located, downloaded, and delivered by intelligent agents, is being greeted with a variety of responses that range from enthusiasm to disparagement and even depression. Much of the criticism focuses on demands for an examination of how the push delivery systems are changing decision makers.

Postman states

Our conversations about nature and about ourselves are conducted in whatever "languages" we find possible and convenient to employ, we do not see nature or intelligence or human motivation or ideology as "it" but only as our languages are. And our languages are our media. Our media are our metaphors. Our metaphors create the content of our culture. [Postman 1985, p. 15]

But there is a danger of backlash as people dislike the content that is pushed and, therefore, give up on new push technologies before they have truly emerged, and well before their benefits are realized. There is the possibility that people will become disenchanted and unplug, before the best applications are developed. There is also a chance that people will suffer information overload and that in turn the stress on their information processing capabilities will cause them to have great difficulty in sorting through what is a useful pull or push technology and what is not. Corporations could conceivably ban certain services from the office as being off-limits since on the surface they do little if anything to further corporate objectives.

Our approach to this material is what Graber (1976) terms an intuitive method of verbal analysis. (Verbal here refers to both oral and written material.) The steps taken in our analysis include setting a goal for the investigation, sampling the verbal output, 
analyzing it for clues, and finally putting it together and interpreting it. The approach has additional layers of complexity since it requires a simultaneous analysis of the context provided by the society as well as the interactions of the various writers and their opinions, and their short and long term objectives. In this article, we define various types or levels of pull and push technologies and discuss their value. Next, using the intuitive method of verbal analysis, we expose some alarming features of pull and push and their implications for individuals, organizations, and societies. We then pose remedies and resolution mechanisms, and if these remedies do not work, we describe the phenomenon of unplugging. Finally, we discuss what may happen in the future.

\section{Information Delivery Systems}

Individuals get the information they need in a couple of ways. They can seek information, hoping that their search process, tools, and training are sufficient to find the information they need. They can also subscribe to delivery systems that bring information to the individual without asking for it. In this case, the individual hopes that the delivery mechanism and content delivered adequately provides the information they need.

Pull technologies involve the seeking process and push technologies consist of the subscription and delivery process. Most individuals depend on a combination of these two methods. We describe each of these processes in the next section.

\subsection{Pull Technologies}

When a person goes to the library, they pull a book off the shelf; similarly, they pull a piece of information from the Web. The word pull connotes grabbing and yanking something from the Internet.

Pull technologies can be simple or complex. Kendall and Kendall (1999a, 1999b) identify four types of pull technologies, beginning with surfing the Net. In this instance, users can browse by clicking on links. Tools available to the surfer include bookmark managers and software and hardware that helps speed up downloading of Webpages. This is called alpha-pull.

The second type of pull, beta-pull, involves using a search engine in order to locate information more effectively. Search engines do not actually search the Web on request. They are merely databases in which information is collected during off-peak times using spiders or bot, short for robot. Users measure effectiveness in terms of precision and recall (Stohr and Viswanathan 1999).

Gamma-pull, the third type of pull, uses a personal assistant, a spider, or bot to search the Web. Spiders or bots do what they are told to do. Therefore they gather information on what the user really wants. This is based on information provided by the individual in a user profile.

The fourth type of pull is very advanced, because an evolutionary agent is used to observe the user's behavior and then modify the searches to more accurately locate the information. By observing the behavior of a user the evolutionary agent forms an opinion 
about what the user really needs, rather than what the user wants. This last type of pull technology is called delta-pull.

The revolution created by the adoption and use of pull technologies will be fueled by how heartily individual users, companies, and the societal culture at large embrace them. Burdensome searching may be partially replaced with the full deployment of deltapull technology, because the evolutionary agent will observe and understand a user's behavior, seeking out information the user needs. Web searches will also be more efficient with full use of delta-pull technology. More satisfying results from initial searches will translate into more effective searchers.

Pull technologies are not the only way for an individual to obtain the information needed for decision making. The other side of information systems delivery is push technology. It mirrors pull technology, but from the user's perspective push technology provides information without having to ask for it. We now discuss push technology and what it means to individuals, organizations, and society.

\subsection{Push Technologies}

Similar to pull technologies, there are four types of push technologies (Kendall and Kendall 1999a, 1999b). The simplest form of push technology can be classified as Webcasting. It is one-to-many, unidirectional, and there is little personalization in this most basic form of push technology. Webcasting is analogous to television broadcasting. Several of the most popular push technologies take the form of screen savers that flash news headlines, stock quotes, and the like.

Webcasting, or alpha-push, can also serve as event reproduction where, according to Apple computer, "The goal is to provide an interactive experience, allowing the user to dig deeper and go behind the scenes of the event itself" (Johnson 1997)-providing real-time event coverage, making live Webcasts not just like being there, but "better than being there."

The second level of push, called beta-push, allows the most flexibility. As the amount of information increases, users will want to filter out unnecessary information that is being pushed on them and corporations will consider some information to be too sensitive to broadcast to every employee. At this level, users can choose channels to include or exclude certain types of content. For example, if seeking information from a news provider, an individual may want to include news and sports, but exclude weather.

A third level, called gamma-push, uses intelligent agents to personalize and filter out messages even further. The agent will adapt user profiles to screen out specific articles based on a set of predetermined criteria. For example, the agent will only display scores from the preselected football teams about which the user expressed interest.

Finally, delta-push, the fourth level, takes this one step further. Services will be custom-designed for the individual, based not only on demographics and data mining (Codd 1995; Gray and Watson 1998; Watson and Haley 1997), but on the behavior of the user. For example, if an evolutionary agent observes the behavior of an individual over time and realizes that the individual is a devoted sports enthusiast, the agent will take this into consideration and push sports news, scores, and information toward the user. In addition, the agent will push commercial advertisements in that direction as well. The important point here is that, based on observation of a user's behavior, the evolutionary agent delivers what the user needs, not merely what the user wants. 


\section{Table 1. The Four Levels of Pull and Push Technologies Illustrate that Users Obtain Information in a Variety of Ways, Each with its Own Set of Consequences}

\begin{tabular}{|l|l|l|}
\hline Level & \multicolumn{1}{|c|}{ Pull Technologies } & \multicolumn{1}{c|}{ Push Technologies } \\
\hline Alpha & $\begin{array}{l}\text { Surfing the Net and using simple } \\
\text { tools like bookmark managers }\end{array}$ & $\begin{array}{l}\text { Viewing Webcasting, which is one- } \\
\text { to-many, impersonal, and uni- } \\
\text { directional }\end{array}$ \\
\hline Beta & $\begin{array}{l}\text { Using search engines to narrow the } \\
\text { search to relevant information }\end{array}$ & $\begin{array}{l}\text { Selecting channels to choose deli- } \\
\text { very of relevant categories of infor- } \\
\text { mation only }\end{array}$ \\
\hline Gamma & $\begin{array}{l}\text { Using a personal assistant or bot } \\
\text { that finds what the user wants, } \\
\text { based on a set of well-defined user } \\
\text { criteria (user profile) }\end{array}$ & $\begin{array}{l}\text { Using intelligent agents, based on a } \\
\text { user's profile, to include informa- } \\
\text { tion the user wants and to screen } \\
\text { out particular information with a } \\
\text { channel that the user does not want }\end{array}$ \\
\hline Delta & $\begin{array}{l}\text { Relying on an evolutionary agent } \\
\text { that changes over time to find what } \\
\text { the user needs }\end{array}$ & $\begin{array}{l}\text { Relying on an evolutionary agent to } \\
\text { observe a user's behavior and then } \\
\text { choose to deliver only the infor- } \\
\text { mation a user really needs }\end{array}$ \\
\hline
\end{tabular}

Table 1 summarizes the four levels of pull and push technologies. Researchers need to reflect on how users obtain information on each of these levels. As one moves from the alpha technologies to the delta technologies, the searching or delivery appears to be much easier, but the consequences need to be considered as well. For an extended discussion about the evolutionary agent see Kendall (1996).

Push technologies will change the orientation and vision of organizations. We are in the early phases of a transforming process. Some of the early corporate leaders have been National Semiconductor, Wheat First Securities, MCI, and Church \& Dwight (the maker of Arm and Hammer baking soda products) (Sliwa and Stedman 1998). Many of these first and early efforts involve the use of corporate intranets to feed information to managers rapidly so that decisions can be made in a timely manner when competition is keen. Additionally, IDS can assist in situations that are unusual, whether highly dynamic or so extreme as to be termed an emergency. For example, MCI uses PointCast to send outage information to 7,000 operations employees. Astound Webcast and Intermind Communicator are both push platforms that can be used with corporate intranets (Strom 1997). Push will make its presence felt in what were often mundane corporate systems such as e-mail. Users in corporations can now create a multimedia experience for the receiver. Where e-mail was originally the province of scientific researchers, Downes and Mui (1998) note its adaptation for advertising and information delivery. Even more startling, they believe that push technology can wind up entirely revamping human communication.

Delta push technology uses memes (Brodie 1996) to replicate and spread content. The advantage of delta push technology is in the successful reproduction of messages that will alter behavior in a way that the provider desires. The copying of a meme in this 
situation can be referred to as a push-virus. For example, advertisers that sponsor Webcasts use gamma push technology to formulate "catchy" songs, ideas, and slogans that stay with users of the media long enough for them to purchase a product or service that has been crystallized in the meme.

The advantage of delta push technology is that push-viruses are so strong that they can result in "catching" an idea, a song, a way of problem solving, and so on that may be beneficial only if large groups of people share in it quickly. Preparing large segments of a population for an impending emergency such as a forecast hurricane is an example of an advantageous use of delta push. Mounting a concentrated effort for solving a large scale transportation strike or unifying negotiators in looking for a solution to a peace process within a short time frame might also be worthwhile uses of delta push technology.

The concept of push technology itself is subject to constant (and not always kind) revision. Office workers may view push as a way to obtain news, weather, and stock quotes without having to click on or call up anything. Librarians may look at push as a data retrieval system. Executives may experience push as a way to gather information needed to make decisions and, perhaps, push will find itself one day at the center of many executive information systems.

As we will see later in this article, use of pull and push technologies harbor major changes for the way that decision makers think, act, and communicate. Businesses using pull and push technologies are competing to allow access or deliver content to users in ways that will make it abundantly apparent that, as Postman writes, "The medium is the metaphor."

Content is determined by structure. Therefore, in the future, pull and push technologies will evolve. Pull technologies will reflect pull content. Push technologies, therefore, are all about push content.

We have just presented the positive aspects of pull and push technologies. The next section examines the darker side of push and pull.

\section{Alarming Aspects of Information Delivery Systems}

All four push technologies and all four pull technologies change the way we think. The counter point to the advantages is provided by the existence of very real threats that can have alarming consequences not just for the individual but for organizations and society as a whole as they work with the pull and push technologies. Just as the alphabet forever changed the written culture, so information technology transforms our culture in ways we are just beginning to contemplate. Postman compares and contrasts the view of the future put forward by Aldous Huxley with that of George Orwell's ubiquitous and, by now, well-known Big Brother:

But in Huxley's vision, no Big Brother is required to deprive people of their autonomy, maturity and history. As he saw it, people will come to love their oppression, to adore the technologies that undo their capacities to think. What Orwell feared were those who would ban books. What Huxley feared was that there would be no reason to ban a book, for there would be no one who wanted to read one. Orwell 
feared those who would deprive us of information. Huxley feared those who would give us so much that we would be reduced to passivity and egoism. Orwell feared the truth would be concealed from us. Huxley feared the truth would be drowned in a sea of irrelevance....In 1984, Huxley added, people are controlled by inflicting pain. In the Brave New World, they are controlled by inflicting pleasure. In short, Orwell feared that what we hate will ruin us. Huxley feared that what we love will ruin us. [Postman 1985, pp. vii-viii]

\subsection{Implications for Individuals}

We know that information does affect human beings; we cannot predict exactly how it will be manifested. For individuals, the potential problems of pull and push technologies include information overload, anxiety, addiction, and disorientation.

We do know that those with addictions to the relationships they strike up on the Internet mirror patterns found in people addicted to other behaviors such as substance abuse, gambling, or compulsive sex. However, in the instance of those addicted to surfing the Web for days on end, normal endeavors and life styles are displaced by Web-based activities, resulting eventually in the loss of jobs, break up of homes, and other socially malignant events.

McArthur (in Kelley 1998, p. G1) states,

There's a great line from John Le Carre, “They're fed up and asking for more." Which is another way of stating that users are experiencing an overload, which they decry, but ironically they are also eager to get ever-increasing amounts of information; more of what they love.

Other thinkers share similar concerns. The contemporary philosopher Heim(1993) wrote, "With a mind-set fixed on information, our attention span shortens. We collect fragments. We become mentally poorer in overall meaning."

How does possessing the capability for 24-hour connectedness influence our behavior with push and pull technologies? Friedman (in Kelley 1998) states that, "It's not clear that (connectedness) enhances the quality of our lives or the productivity of our work lives." Others are amazed at the potential for electronically induced "soul sickness"(Crabb as quoted in Kelley 1998) of exhibitionists and voyeurs alike as people procure Web cameras to exhibit every manner of bodily function to viewers on the Internet.

The stress of togetherness causes illness and dysfunction or lack of functioning in any human culture (Kelley 1998, p. G8). The positive aspects of having a private time and place to oneself become evident.

A steady onslaught of broadcast information with no customization has been termed a "wasted expression" by Reid (1996, p. 10), who reminds us that

All pushed information inevitably reaches many people who just aren't interested in it. Consider the Sunday newspaper... The many misses of 
pushed communication mean that every spot on hit is expensive to reach, and this expense prices a tremendous amount of would-be content out of the distribution channel.

Years ago there was a comedic play, written by the comedian and playwright Ben Elton, produced in London, called Gasping. In it, big business interests had created a commodity of the very air we breathe. Citizens were literally gasping for air, because the air market had been cornered by ruthless business moguls.

When we see individuals disconnecting, we might be able to recognize that those individuals are themselves "gasping." Gasping for the air of the old order, the old culture.

\subsection{Implications for Organizations}

The use of alpha push on Webcasts such as PointCast and others may result in a junk culture where everything is pushed to the user with little discrimination and, because the users have already discounted the value of the content (since what is conveyed through the medium of alpha push is so often junk), content is largely ignored. Alpha push technologies may be passed over by users as being too mass oriented; as being both "high tech and low touch" in an era when personalization and customization (whether real or counterfeit) are prized. Vast sums of money are spent to push content that is irrelevant.

Another disadvantage of delta push is lack of access or denied access because of too small of a bandwidth. A message such as "Server too busy" means that the information cannot be accessed.

\subsection{Implications for Society}

Wise researchers and commentators have not let the advent of mass media pass unremarked. Because push and pull technologies alter our discourse and thereby the way that we think, we must acknowledge that the media with which we engage each other are not empty vessels waiting to be filled with good or bad content. Rather they are the revolution in and of themselves. Postman writes credibly in arguing for the belief that the change has already taken place:
We have reached... a critical mass in that electronic media have decisively and irreversibly changed the character of our symbolic environment. We are now a culture whose information, ideas and epistemology are given form by television, but not by the printed word...print is now a residual epistemology, and it will remain so, aided to some extent by the computer, and newspapers and magazines made to look like television screens. [Postman 1985, pp. 27-28]

One way to discuss what happens with delta push technology is to use the metaphor of viruses that mutate and change, infecting those susceptible rapidly, with no known cure. For instance, delta push technology may feature evolving memes with an evil 
message of ethnic hate, that eventually stiffen a nation's resolve to go to war against a neighboring country, or even its own citizens. With the use of delta push technology, the evolving memes may be too overwhelmingly memorable to permit other forms of thought.

\section{Remedies and Resolution of IDS Threats}

What are the remedies that can be taken so that the darker side of IDS do not prevail? Our analysis and interpretation reveal that there are several steps that can be taken and that many of these remedies are already being employed on a small, unsystematic basis, but still with good results. What is needed is an adoption and application of these coping strategies in a more systematic and all-encompassing way.

One possible remedy is to focus the attention of the users on understanding the value of the IDS technology. Problems often disappear when people begin to appreciate what technology has to offer. Another effective remedy is the education of all people; not just superficially so that the tangible uses of information technology are harnessed, but education in a deeper fashion so that the actual cultural departure represented by changing to an information society can be grasped. A third remedy is to use humor to satirize the changing activities, priorities, and livelihoods of users. Since humor is a relentlessly human exercise, it provides a strong countervailing force in response to new technologies.

\subsection{Striving Toward Understanding the Value of IDS}

One of the key remedies that can be taken to quell the frightening aspects of pull and push technologies is that of understanding, and then valuing, what we are up against. Postman writes:

Public consciousness has not yet assimilated the point that technology is ideology...this, in spite of the fact that before our very eyes technology has altered every aspect of life in America during the past eighty years.... To be unaware that a technology comes equipped with a program for social change, to maintain that technology is neutral, to make the assumption that technology is always a friend to culture, is, at this late hour, stupidity plain and simple. [Postman 1985, p. 157]

Johnson states that "One of the central problems with push media is that it takes away much of the users' control without providing many of the benefits that traditional broadcasting does in the form of solid linear narrative." In other words, push technologies are designed to be in front of you but otherwise unobtrusive (placed on pagers or screen savers, etc.); they are "there" without causing disruption to a typical task. However, because of this, push media does not do a good job of telling stories. This sounds trivial but is actually quite important. Strength and presence of narrative alters the passive nature of TV and radio, and makes them "work" (Johnson 1997). Others would agree, noting that current television news in the U.S. has an insatiable appetite for what The Economist (July 1998) has dubbed "water-cooler stories." The key criteria for qualifying as a water-cooler story is that it "must have recognizable characters and a 
developing drama." Thus the point is made that editors, who are normally quite competitive, fulfill their competitive assignment by falling all over each other spending large budgets on getting "the same old story."

\subsection{Educating Users and Providers about Designing IDS}

One of the remedies for the alarming aspects of pull and push technologies is the education of all people who are impacted by them. We need to educate people about how media changes the structure of our discourse. We can begin by educating decision makers and other users of pull media about the need for balance.

We can also educate push providers about the need for balance. Perhaps pushing a coherent story is more important than displaying a fragment. For example, although CNN Headline News has added a one-sentence headline to the bottom of its screen, which is continuously changing, stories are often incomprehensible because of the small amount of display space permitted. An additional self-imposed constraint seems to be that the headline must fit at the bottom of the screen without benefit of expansion via scrawling. Balance in stories presented like this is utterly lacking, and this lack can be addressed.

\subsection{Using Humor to Alleviate the Stress in IDS Implementation}

Edward de Bono (1992) suggests that humor is the heart of creativity. Postman asserts that we should laugh at ourselves and even parody ourselves. With tongue in cheek, he also notes that this last assumes that we can distinguish between parody and some other event that might be picked up and played out through the media. Kendall (1997) found that information systems designers could use the posting of cartoon humor by users to assess the gap between the actual versus intended addressing of critical success factors important to systems implementation.

The ability to regard the eight pull and push technologies as often producing humorous results, along with their capability to pose serious threats, puts the designer in a superior position to understand the complexity of what they are doing and the possible influence of their push and pull designs on the human spirit.

\section{Unplugging}

Unplugging is a reaction to overload. An example of unplugging is when an individual feels inordinate pressure from being connected to technology on a 24-hour, seven day per week basis and subsequently takes some sort of action to disconnect from the artificial word of technology. The individual resumes life in the physical world, the one populated with people, not just machines.

Unplugging can take on different meanings at the individual, organizational, and societal levels. We will discuss each of these in turn. 


\subsection{Meaning for Individuals}

Individuals may have to seek real life (high touch, low tech) experiences instead of being "plugged in." Heim has written about information fixation and has stated that what people did while unplugged was more important than the length of time they spent away from technology. He notes that technology retrains our nervous system, creating a new pace and tempo to which we adapt, but with which we could ultimately be uncomfortable. Many spiritual groups ask their participants to unplug for the duration of their retreats (Yuen 1998).

We envision entire technology-free sectors (e.g., public parks) where people can go and be unplugged without worrying that they will be accosted by others being able to "reach" them electronically in the wilderness. These parks could include places for retreats, concerts, and hideaways. It is incumbent on the new generation to create cultural norms that encourage thinkers to think, actors to act, and so on where the structure of thought is not dictated by the incessant and ubiquitous interactions with Web push and pull technologies.

This suggestion is not in any way to be construed as Luddite in origin. Quite the contrary. If we are to continue being creative, we need time away from push and pull technologies to develop new paradigms and innovative approaches to solving our problems (some of which paradoxically arise due to our interactions with new technologies). We need time to reflect. Quite possibly, we even need time alone. Once we can safely unplug, our creative and innovative solutions to new and old problems should be promising enough for the society to want to continue to inculcate this practice. The fruits should be plentiful, and they should be obvious.

\subsection{Meaning for Organizations}

Picarille (1997) acknowledges increasing information overload among users of push technology on the Internet, intranets, and extranets. Although one remedy has been characterized as "pushing back" by simply getting rid of their multiple channels, Picarille notes that "corporate users are looking for better ways to manage the critical information they receive."

In place of electronic connectivity, the organization can legitimize formal or informal face-to-face time when certain thinking forms can be introduced. These might include brainstorming or other ways to stimulate creativity or evaluate new ideas (see, for example, the negative assessment step suggested by Abu Hamdieh and Kendall [1999] for evaluation of systems projects.) Somewhat surprisingly, planned face-to-face activities that take managers completely out of the reach of push and pull systems are already the norm for executives in some companies such as Microsoft.

Other researchers and philosophers have suggested that the topics that occupy managers' minds during times of being unconnected are every bit as important as the length of time spent away (Heim 1993). Another example of a corporate remedy is that supplied by National Semiconductor, who added its own channel to PointCast, which they have called National Advisor. Three streams of product-related data are featured: (1) daily traditional sales and order information recorded by field sales staff; (2) data 
captured on their Website, which specifically captures the frequency of visits, keeps track of what product information customers are looking for, and also which items are requested more often as samples; and (3) analysis of e-mail questions that are fielded on the Web which are sorted according to recognizable product categories (Cronin 1997).

The values of the corporation should be such that (most) employees are not expected to exist with 24 hour connectivity. Just as connectivity can be part of the strategic IS plan, so can sanctioned time away from e-mail and the incessant interaction of collaborative work systems.

\subsection{Meaning for Society}

How will push and pull technologies shape and impact the existence and persistence of particular countries, their boundaries, their world views? The world will undoubtedly experience problems and face decisions resulting from information overload and a diversity of perspectives because of push and pull technologies. Neither do we know what the effects are of continuous connection, instant access, or even bombardment with information. In some ways, we know more about what happens to people totally deprived of sensory input, for example, than what happens to a society deluged with information.

\section{Conclusions}

After the necessities of love and loyalty, what is one quality we would seek in a friend? Perhaps it is their ability to know what it is we like, in other words, the information and activities that we uniquely prefer. We disclose these preferences to our friend, and they remember and oblige. They observe us further, watch our behavior, and then guide us as we seek our objectives. This is what we can expect of delta-pull technology in the future.

Sometimes, if we have been friends for a long while, our friends intuit what we want, without requiring us to utter a word. Then, rather than guiding us, they bring us what we need when we need it. In the future, delta-push technology will do just this.

Computers using software based in part on intelligent, evolutionary agents can simultaneously deliver information to decision makers on a variety of topics. One of our most valued aspects of friendship can be addressed by the right system. What happens to our expectations when this occurs? What do pull and push technology mean for the way that we seek information and the way decision makers perceive it?

Similarly, for pull technology, the evolutionary agent helps users to seek out exactly the information they need on the World Wide Web or the Internet, and to download it to their computers, to use it at their convenience. Pull technology allows users to have the world at their fingertips, whenever they need it.

The story of the sorcerer's apprentice is illustrative of what happens when push or pull technologies run amok. The sorcerer has power to command an intelligent agent to perform a certain behavior. Without feedback, the apprentice continues unchecked until it has carried enough water to fill an entire room. Then, not only does the apprentice accomplish a task, but continues executing a task to the point where the results of engaging with the technology actually becomes harmful. 
What does the future hold for researchers of push and pull technologies? What will corporations and the cultures within which they exist do when confronted with emerging technologies? Will our accepted models of adoption and use of technologies hold true? Perhaps instead we will experience a revolution of adoption processes as well as the revolutionary technologies. Push and pull technologies are being greeted with a wide spectrum of reactions. There are users and organizations that are fascinated with IDS. There are small forays into technological innovation and adoption (almost too tentative to be called experiments) by some organizations. Some companies have encouraged toying with IDS, but it is almost as if invoking the game precludes them from imagining wider implications. Indeed, their view is that employees will likely tire with the new toy of push and pull technologies, abandoning it for whatever the next fad is. In this scenario, IDS are not so much greeted with alarm as with eventual boredom, lapsing into disuse.

Our thought is that, since information delivery systems (IDS) will continue to emerge and evolve, we need not assume that the evolution and spread of this new technology will unfold in the same old (predictable) patterns. One way that IDS can gain acceptance on the grass roots level is by making all of the personal information devices such as palmtops, digital watches, pagers, mobile phones (and other intriguing combinations) deliver a greater quantity of customized information in a more personalized manner. This is a departure from older models of the adoption of new information technologies, which dictated that because of the cost of the technology, it would be a mass medium, broadcasting to the masses, impersonally targeting non-segmented groups. Portable devices and hand held devices will be able to communicate to each other in an ad hoc way. Old barriers to mass media, including the clumsy footprint left by required cables, may not be viewed as barriers any longer.

What we learn from the birth and growth of push and pull technologies is both distressing and invigorating. We recommend that we understand, educate, and use humor in order to really come to grips with what is happening. We are undergoing a revolution of dramatic proportions. Push and pull technologies will enable the transformation of the print culture. Very few people understand the proportions of the revolution. As Postman writes, "Only through a deep and unfailing awareness of the structure and effects of information, through a demystification of media, is there any hope of our gaining some measure of control over television, or the computer, or any other medium." We heartily concur. By considering pull and push technologies at their most alarming and then examining the possible remedies, they can be demystified and, in many cases, put to good use for individuals, organizations, and society as a whole.

\section{References}

Abu Hamdieh, and Kendall, J. E. "Assessing the Negative Effects of Proposed Information Systems: A Method Based on de Bono's Thinking Hats," in Proceedings of the Fifth International Meeting of the Decision Sciences Institute, K. Zopounidis (ed.), Athens, Greece, 1999.

Brodie, R. Virus of the Mind. Seattle, WA: Integral Press, 1996.

Codd, E. F. "Twelve Rules for On-Line Analytic Processing," Computerworld, April 13, 1995, pp. 84-87. 
Cronin, M. "Using The Web To Push Key Data To Decision Makers," Fortune (136:6), September 29, 1997, p. 254.

De Bono, E. Serious Creativity: Using the Power of Lateral Thinking to Create New Ideas. New York: Harper Business, 1992.

Downes, L., and Mui, C. Unleashing The Killer App: Digital Strategies For Market Dominance. Boston: Harvard Business School Press, 1998.

Graber, D. A. Verbal Behavior and Politics. Chicago: University of Illinois Press, 1976.

Gray, P., and Watson, H. J. Decision Support in the Data Warehouse. Upper Saddle River, NJ: Prentice Hall, 1998.

Heim, M. The Metaphysics of Birtual Reality. New York: Oxford University Press, 1993.

Johnson, M. R. "Webcasting," 1997 (http//www.mindspring.com/cityzoo/mjohnson/ papers/webcasting/introduction.html; accessed on July 1, 1998).

Kelley, T. "Only Disconnect (for a While, Anyway): A Few of the Well-connected Who Take Time Off from E-mail, and Survive," The New York Times, Thursday, June 28, 1998, pp. G1, G8.

Kendall, J. E. "Examining the Relationship Between Computer Cartoons and Factors in Information Systems Use, Success, and Failure: Visual Evidence of Met and Unmet Expectations," The DATA BASE for Advances in Information Systems (28:2), 1997, pp. 113126.

Kendall, J. E., and Kendall, K. E. (1999) "Information Delivery Systems: An Exploration of Web Push and Pull Technologies," Communications of AIS (1:14), April 23, 1999.

Kendall, J. E., and Kendall, K. E. "Web Pull and Push Technologies: The Emergence and Future of Information Delivery Systems," in Emerging Information Technologies: Improving Decisions, Cooperation, and Infrastructure, K. E. Kendall (ed.), Thousand Oaks, CA: SAGE Publications, Inc., 1999, pp. 265-288.

Kendall, K. "Artificial Intelligence and Götterdämerung: The Evolutionary Paradigm of the Future," The DATA BASE for Advances in Information Systems (27:4), Fall 1996, pp. 99115.

Picarille, L. "Push Comes to Shove on the Web," Computer Reseller News (749) August 11, 1997, pp. 113-114.

Postman, N. Amusing Ourselves To Death: Public Discourse in the Age of Show Business. New York: Penguin Books, 1985.

Reid, R. H. Architects of the Web: 1,000 Days that Built the Future of Business. New York: John Wiley \& Sons, Inc., 1996.

Richardson, D. "Data Broadcasting- The Ultimate Push Technology?" IEE Conference Publication, 447, Stevenage, UK: IEE, 1997, pp. 36-42.

Sliwa, C., and Stedman, C. “'Push' Gets Pulled Onto Intranets," Computerworld (32:12), March 23, 1998, p. 6.

Stohr, E. A., and Viswanathan, S. "Recommendation Systems: Decision Support for the Information Economy “ in Emerging Information Technologies: Improving Decisions, Cooperation, and Infrastructure, K. E. Kendall (ed.). Thousand Oaks, CA: SAGE Publications, Inc., 1999.

Strom, D. "Tune in to the Company Channel," Windows Sources, (5:9), 1997, pp. 149-158 passim.

The Economist. "The News Business," July 4, 1998, pp. 17-19.

Watson, H. J., and Haley, B. “A Framework for Data Warehousing," Data Warehousing Journal (2:1), 1997, pp. 10-17.

Yuen, E. "An Ideal Buddhist Vacation: Travel Combined with Mindfulness Meditation," Philadelphia Inquirer, Sunday, July 12, 1998, p. H7. 


\section{About the Authors}

Julie E. Kendall, Ph. D., is an associate professor of MIS in the School of BusinessCamden, Rutgers University and is currently the Vice-Chair of IFIP WG 8.2. Julie has published in MIS Quarterly, Decision Sciences, Information \& Management, Organization Studies, and many other journals. Additionally, Julie has recently co-authored a college textbook with Kenneth E. Kendall, Systems Analysis and Design, fourth edition, published by Prentice Hall. She has served as a functional editor of MIS for Interfaces and as an associate editor for MIS Quarterly. She is on the editorial boards of Journal of AIS, Journal of Management Systems, and Journal of Database Management, and is on the editorial review board of Information Resource Management Journal. She was recently elected to serve as Vice President for Decision Sciences Institute. Julie's research interests include developing innovative qualitative approaches for information systems researchers interested in systems analysis and design. She is researching societal implications of push and pull technologies. Julie can be reached by e-mail at julie@ thekendalls.org; her home page can be accessed at www.thekendalls.org.

Kenneth E. Kendall, Ph. D., is a professor of Information Systems in the School of Business-Camden, Rutgers University. He recently co-authored a text, Systems Analysis and Design, fourth edition, published by Prentice Hall and edited Emerging Information Technologies: Improving Decisions, Cooperation, and Infrastructure for Sage Publications, Inc. Ken has had his research published in MIS Quarterly, Management Science, Operations Research, Decision Sciences, Information \& Management, and many other journals. $\mathrm{He}$ is one of the founders of the International Conference on Information Systems (ICIS). Ken is the past Chair of IFIP Working Group 8.2 and served as a Vice President for the Decision Sciences Institute. He is the MIS editor for the Journal of Management Systems and an Associate Editor for Decision Sciences, the Information Systems Journal, and the Information Resources Management Journal. He has also served as a functional editor of MIS for Interfaces. Ken's research focuses on studying push and pull technologies and developing new tools for systems analysis and design. He can be reached by e-mail at ken@thekendalls.org; his home page can be accessed at www.thekendalls.org. 